\title{
Examination of monolingual (English) and bilingual (English/Spanish; English/Urdu) children's syntactic awareness
}

\author{
Denise DAVIDSON ${ }^{1 *}$, Sandra B. VANEGAS ${ }^{2}$, Elizabeth HILVERT ${ }^{1}$, Vanessa R. RAINEY ${ }^{3}$, \\ and Ieva MISIUNAITE ${ }^{1}$ \\ ${ }^{1}$ Loyola University, Chicago, USA, ${ }^{2}$ Texas State University, USA, and ${ }^{3}$ University of West Florida, USA \\ ${ }^{*}$ Corresponding author. Department of Psychology, Loyola University Chicago, 1032 W. Sheridan Rd., \\ Chicago, IL USA. e-mail: ddavids@luc.edu
}

(Received 21 November 2017; revised 3 October 2018; accepted 25 January 2019; first published online 14 March 2019)

\begin{abstract}
In this study, monolingual (English) and bilingual (English/Spanish, English/Urdu) fiveand six-year-old children completed a grammaticality judgment test in order to assess their awareness of the grammaticality of two types of syntactic constructions in English: word order and gender representation. All children were better at detecting grammatically correct and incorrect word order constructions than gender constructions, regardless of language group. In fact, bilingualism per se did not impact the results as much as receptive vocabulary range. For example, children with the highest receptive vocabulary scores were more accurate in detecting incorrect word order constructions (i.e., word order violations, semantic anomalies) and incorrect gender agreement than children in the lower receptive vocabulary ranges. However, no differences were found between the ranges for ambiguous gender constructions. These results highlight the importance of receptive vocabulary ability on syntactic awareness performance, regardless of language group.
\end{abstract}

Keywords: syntactic awareness; bilingualism; receptive vocabulary

\section{Introduction}

Syntactic awareness is a type of metalinguistic awareness that refers to one's knowledge and awareness about the grammatical structure of sentences in a language, including the order of words in a sentence (Reder, Marec-Breton, Gombert, \& Demont, 2013). It can be contrasted with morphological awareness, or the ability to reflect on and manipulate morphological units within words (Carlisle, 2003; McBride-Chang et al., 2005), and phonological awareness, or the ability to identify and manipulate sounds within words (Goswami, Ziegler, \& Richardson, 2005). In general, each of these metalinguistic skills requires that a language speaker is able to distance him or herself "from the content of speech in order to pay attention to the structural features of a language and to the language's properties as an object" (Reder et al., 2013, p. 687). 
Past research has shown that these metalinguistic skills are closely related to literacy (e.g., Gombert, 1992; McGuinness, 2005; Nunes \& Bryant, 2004). Syntactic awareness, in particular, has been associated with both language and reading proficiency (Bialystok \& Barac, 2013; Gaux \& Gombert, 1999; Guo, Roehrig, \& Williams, 2011; Katz, 2004; Mokhtari \& Thompson, 2006; Nation \& Snowling, 2000). Cain (2007), for example, showed that reading and syntactic awareness shared unique variance not explained by other variables when assessed in eight- and ten-year-old children. Guo et al. (2011) found that in adults over $90 \%$ of the variance in their reading comprehension scores could be explained by syntactic awareness and vocabulary ability. According to Gaux and Gombert (1999), syntactic awareness may facilitate reading in a number of ways, including syntactic parsing, which enables readers to use the function of the word to identify sentence structure and word relations to achieve reading comprehension.

\section{Development of syntactic awareness}

Syntactic awareness, along with other metalinguistic skills (e.g., morphological and phonological awareness), are initially present at an implicit level, or 'epilinguistic level' (Gaux \& Gombert, 1999; Gombert, 1992, 2003; see also Davidson, Vanegas, Hilvert, \& Misiunaite, 2017). These epilinguistic abilities are organized and stored in long-term memory, although young children may not be consciously aware of them (Simard, Labelle, \& Bergeron, 2017). That is, in describing the development of metalinguistic skills, Gombert distinguishes between the acquisition of primary linguistic skills, in which "correspondences between linguistic forms and reinforced pragmatic contexts are stored in an implicit and instance-bound format" (2003, p. 3), and an epilinguistic phase in which regularities are extracted. Such an implicit monitoring process in turn leads to epilinguistic control and eventually metalinguistic awareness. According to Gombert, once these processes become metalinguistic, one can then consciously reflect on and manipulate the structures of a language when accomplishing a linguistic task (e.g., such as replicating grammatical errors in a sentence on a syntactic awareness task).

Past research has shown that the development of epilinguistic processing, particularly epilinguistic control, shows major developments between four and eight years of age (Tunmer \& Grieve, 1984). In terms of syntactic awareness in particular, Tunmer and Grieve argued that judgments of grammatically correct and incorrect sentences develop in three successive stages: (1) around the age of two to three years, judgments are based on whether the child understands or does not understand the sentence; (2) at about four to five years of age, the criteria of content becomes predominant in children's judgments; and (3) it is not until six to seven years of age that the child is able to separate the form of a sentence from its content. In doing so, this allows the child to base his or her judgments on linguistic criteria alone. This is supported by research that shows children develop the ability to consciously reflect on the structures of sentences from about six to seven years onwards (Bialystok, 2001). However, these processes continue to develop throughout middle childhood (Gombert, 1992).

\section{Relations between syntactic awareness and receptive vocabulary in monolingual and bilingual children}

Many studies and conceptualizations of syntactic awareness and its development have considered the monolingual experience as the normative developmental trajectory. 
However, there is a growing consensus that the bilingual experience may, in fact, alter the developmental trajectory of a number of linguistic skills, including syntactic awareness (Bialystok, 2001). This is important because monolingualism is no longer the norm worldwide (Grosjean, 2013). To date, there are inconsistencies regarding how bilingual children perform on syntactic awareness measures in comparison to their monolingual peers. In some cases, a bilingual advantage has been found (e.g., Bialystok, 1986; Cromdal, 1999; Davidson, Raschke, \& Pervez, 2010; Foursha-Stevenson \& Nicoladis, 2011), whereas other studies have not found differences between monolingual and bilingual children on syntactic awareness measures (Simard, Fortier, \& Foucambert, 2013). Moreover, a handful of studies have shown a bilingual disadvantage on measures of syntactic awareness (e.g., Da Fontoura \& Siegel, 1995; Lipka, Siegel, \& Vukovic, 2005). As others have noted (Gleitman \& Gleitman, 1979; Hirsch-Pasek, Gleitman, \& Gleitman, 1978), individual and task characteristics may explain these mixed findings.

One individual characteristic that may play a role is whether the syntactic awareness measure is being administered to the bilingual child in his or her dominant language. Bilinguals are often not equally proficient in each of their languages because they may use their languages for different reasons, in different contexts, and with different people (e.g., Gathercole \& Thomas, 2005; Grosjean, 2015; Grosjean \& Li, 2013; Yip, 2013). In fact, bilingual children may show dominance in one language over another, yet proficiency in their dominant language may still be subpar or lacking in comparison to their monolingual peers. Thus, testing a bilingual child in his or her dominant language may not be sufficient in identifying monolingual-bilingual differences on syntactic awareness measures. It is our contention that bilingual children must demonstrate close to age-level proficiency in receptive vocabulary knowledge in their dominant language in order for monolingual-bilingual differences on syntactic awareness measures to be adequately compared.

Although there are a number of ways to measure language dominance, we agree with the position of Bachman and colleagues who state that the lexicon may be the core component of language ability (Bachman, 1990; Bachman \& Palmer, 1996). For example, the lexicon is important because the development of syntactic acquisition may be dependent upon the development of vocabulary (Bates \& Goodman, 1997; Chomsky, 1995). More specifically, measures of receptive vocabulary (i.e., all the words one can recognize through either hearing or reading them) may be particularly informative of one's language dominance, as they may capture more of what the child knows than measures of productive vocabulary (Nation, 2013). Moreover, research has shown that measures of receptive vocabulary can be used to examine language dominance in both monolingual and bilingual children (Bialystok, Luk, Peets, \& Yang, 2010). As such, receptive vocabulary ability has been identified as an important indicator of language proficiency (e.g., Genesee, Nicoladis, \& Paradis, 1995; Nicoladis, 2006). Past research has also found evidence of a positive relation between receptive vocabulary ability and syntactic awareness. For example, research has shown that bilingual children may have an advantage on syntactic awareness measures in relation to their monolingual peers, but only when bilingual children are proficient on receptive vocabulary measures in both languages (Cromdal, 1999; Galambos \& Hakuta, 1988). Additionally, Davidson et al. (2010) found that when bilingual (English/Urdu) children were tested in their dominant language (English) and demonstrated age-level English receptive vocabulary proficiency, they were better at detecting grammatically incorrect syntactic constructions than their 
monolingual peers. Similarly, bilingual (Swedish/English) children who were highly proficient in vocabulary abilities in both languages performed better on a syntactic grammaticality measure than less proficient bilingual children who performed the same as their monolingual peers (Cromdal, 1999). Finally, these findings appear to extend beyond syntactic awareness abilities to other metalinguistic abilities as well. For example, Davidson et al. (2017) found that, for morphosyntactic awareness, language group differences between monolingual (English) and bilingual children (English/Spanish, English/Urdu) were minimized when bilingual children exhibited at least average receptive vocabulary proficiency and when more difficult morphosyntactic structures were assessed.

Strong connections between syntactic awareness and vocabulary development are predicted by the metalinguistic hypothesis. According to the metalinguistic hypothesis, syntactic awareness and vocabulary development are closely connected because each requires the child to pay attention to the context of words in spoken and written language (Nagy, 2007). As Nagy notes, "children's difficulties in learning the meaning of a word often stem from a failure to reflect on the information provided by the structure of the sentence - that is, from a lack of syntactic awareness" (2007, p. 58). In fact, greater vocabulary proficiency in a language is often linked with more efficient lexical and syntactic processing in that language (e.g., Marchman, Fernald, \& Hurtado, 2010; Moyle, Ellis Weismer, Lindstrom, \& Evans, 2007).

\section{Measuring syntactic awareness: challenges and frameworks}

In addition to individual characteristics such as language proficiency, performance of monolingual and bilingual children on syntactic awareness tasks may vary based on the type of measure administered (Simard et al., 2017). Moreover, measuring syntactic awareness can be challenging because measures of syntactic awareness can take many forms (Simard et al., 2013, 2017). As Simard et al. (2013) suggest, there is no consensus among researchers about what measures really allow for the assessment of syntactic awareness. As they note, syntactic awareness tasks tap into meta-syntactic abilities through the process of "judgment, correction, localization, explanation, completion, repetition and replication tasks" (2013, p. 20). For example, one can use a grammaticality judgment task that requires only a simple detection of grammatically correct and incorrect syntactic structures in a sentence (Bialystok, 2001). In contrast, others have argued that the only true task that measures syntactic awareness is the replication task, because a correct replication of an error provides information that the participant is explicitly aware of and has analyzed the language in order to intentionally reproduce the error (Gaux \& Gombert, 1999).

Perhaps one way to reconcile these rather opposing views is to consider the framework posited by Bialystok (2001), and others (Ricciardelli, 1993; Simard \& Fortier, 2007; Simard et al., 2013). More specifically, two distinct skills can be called upon by syntactic awareness measures: (1) the level of analysis of (syntactic) knowledge, and (2) the level of attentional control (e.g., Bialystok, 2001). For example, on the grammaticality judgment test that requires one to judge the grammaticality of spoken sentences, both the level of attentional control and level of knowledge analysis are low. However, asking children to explain why a sentence may be grammatically correct or incorrect increases the level of knowledge analysis required by the task (Simard et al., 2013). In contrast, on the replication of errors task, the individual must be able to identify and produce the same grammatical error 
in another sentence, requiring both high levels of knowledge analysis and attentional control (see Simard et al., 2013, for a discussion). As noted earlier, using the strictest definition of syntactic awareness, only the replication of error task would adequately gauge a child's syntactic awareness (Gaux \& Gombert, 1999; Simard et al., 2013). The problem is that very few young children can complete this task, so it may not be an appropriate measure of early syntactic awareness in young children (e.g., Davidson et al., 2010).

Another way of conceptualizing syntactic awareness, and determining the best way to measure it, is to keep in mind the distinction between epilinguistic and metalinguistic behaviors that are being assessed on various syntactic awareness tasks (see Simard et al., 2017, for a complete discussion). According to Gombert (1992, 1999) and others (Tunmer \& Grieve, 1984), the ability to judge sentences as grammatical, such as that shown on the grammatical judgment task, is episyntactic in nature because the judgment may be based on the dissonance of the utterance within the pragmatic or semantic context, rather than on conscious reflection about syntax per se. Others, however, have accepted the grammaticality judgment task as metasyntactic in nature, at least under several conditions, such as when a child must not only detect, but also explain grammatical errors (Davidson et al., 2017; Simard et al., 2013).

When working with young children (three- to six-year olds), it has been found that they can distinguish between grammatically correct and incorrect instances of syntactic structures in spoken language at greater than chance, although neither monolingual or bilingual children were able to explain the grammatical error they noted, suggesting a more epilinguistic nature existing in this age group (Davidson et al., 2010). In contrast, Galambos and Goldin-Meadow (1990) found developmental differences in the quality of grammar-oriented explanations, with the most significant improvement occurring between five and seven years of age. However, in their research, no differences were found in the explanations provided by monolingual and bilingual children. Of interest in the present research was whether children between five and six years of age can both detect grammatical errors AND provide an explanation of the errors, and whether differences exist between monolingual and bilingual children's ability to do so.

\section{Syntactic awareness and cross-linguistic influence}

In addition to individual and task characteristics, performance on syntactic awareness measures may vary as a function of the cross-linguistic influence of one language on another (Paradis, 2010; Paradis, Nicoladis, Crago, \& Genesee, 2011). This may occur in several ways. First, syntactic differences between languages may heighten bilingual children's awareness of the differences between their languages, subsequently improving their ability to detect grammatically correct and incorrect syntactic structures on a grammaticality judgment task. Conversely, bilingual children may perform less well than monolingual children if they have yet to fully establish awareness of these differences. Second, overlap between languages in terms of syntactic constructions may increase bilingual children's awareness of the well-formedness of these constructions (Paradis, 2010). Finally, ambiguity may exist between languages in terms of a syntactic construction. For example, one language might possess a certain syntactic construction, whereas the other language might possess the same construction, but allow other ways of constructing the sentence as well (see Foursha-Stevenson \& Nicoladis, 2011, for a discussion). As a result, children may overgeneralize from their dominant language to their less dominant language when judging the grammaticality of constructions. 
To explore each of these possibilities, in the present research we assessed syntactic awareness in monolingual (English) and two groups of bilingual (English/Spanish, English/Urdu) children using a grammaticality judgment test. Specifically, we assessed monolingual and bilingual children's ability to judge the grammaticality of two types of syntactic structures within a sentence: traditional word order violations (e.g., -SOV) and natural gender violations that occurred at the sentence level. Traditionally, these latter violations are considered morphemic violations (Gaux \& Gombert, 1999). However, we have adopted a broader interpretation because gender agreement can lead to violations at the sentence level. Moreover, these structures (word order, gender) were chosen because they can vary in terms of how they are represented in English, Spanish, and Urdu.

In terms of word order, English and Spanish share a similar word order structure: both are classified as a subject-verb-object (-SVO) language because the subject, verb, and object appear in this order. ${ }^{1}$ Thus, structural overlap between languages may increase the likelihood that bilingual children are aware of the correct form of the syntactic structure. Evidence for this hypothesis can be found in a recent study on another metalinguistic skill: morphosyntactic awareness (Davidson et al., 2017). In the Davidson et al. study, English/Spanish-speaking bilingual children were better at detecting the grammaticality of plurals in English that were consistent with the formation of plurals in Spanish than were monolingual English-speaking children. This effect, however, was only found at the highest receptive vocabulary range in their sample. At the lowest range of receptive vocabulary ability, bilingual children performed more poorly than monolinguals.

Urdu, in contrast to English and Spanish, is classified as a Subject-Object-Verb (-SOV) language (Ahmed \& Alvi, 2002). Because of the lack of structural overlap and ambiguity between English and Urdu in terms of word order, one might predict that bilingual English/Urdu-speaking children will be less likely to generalize, and therefore may be less able to identify grammatical violations of word order constructions, than bilingual English/Spanish-speaking children. Conversely, word order may be represented in separate conceptual systems in the bilingual speaker. That is, keeping track of these separate systems may heighten bilingual children's awareness of grammatically correct, and in particular, grammatically incorrect constructions. This prediction is based on an extrapolation of the languageautonomy hypothesis. According to the language-autonomy hypothesis, a bilingual speaker is believed to have autonomous conceptual systems for each of his/her languages to the extent that knowledge about the structure of each language is independent of the other (Costa, Kovacic, Frank, \& Caramazza, 2003). In fact, even when languages are similar in the form of a syntactic structure (e.g., both use masculine and feminine determiner forms), evidence for independent representation of gender in each language has been found (Costa et al., 2003).

In terms of gender, it is important to distinguish between grammatical gender and natural gender because the way in which they are represented and used can also vary between languages. Grammatical gender classifies all nouns into two or more (i.e.,

\footnotetext{
${ }^{1}$ Note, however, that in Spanish there is more flexibility. In Spanish, ordinary statements can start with the subject, the verb, or the object (Erichsen, 2012). To illustrate, all of the following sentences are possible as a translation of "Diana wrote this novel": "Diana escribió esta novela" (subject first), "Escribió Diana esta novela" (verb first), and "Esta novela la escribió Diana" (object first). The flexibility of word order in Spanish allows for shifts in meaning and emphasis depending on the context.
} 
male, female, neutral) grammatical gender classes, with the assignment of grammatical gender a language-based convention, whereas natural gender indicates the biological gender of the referent. In the present study, we were interested in natural gender as English does not have a grammatical gender system (Kurinski \& Sera, 2011), and all children were tested in English.

In English, natural gender is primarily denoted by pronouns (Jarvis \& Pavlenko, 2008). In contrast, in many other languages, natural gender is expressed by adjective and noun endings, articles, and pronouns. According to Kurinski and Sera (2011), "in modern Spanish, all nouns are categorized into two classes, masculine and feminine. Spanish determiners and many adjectives have feminine and masculine forms that are generally concordant with their corresponding nouns in both singular and plural forms" (2011, p. 204). In general, these forms are fixed, although societal and cultural changes have resulted in changes in the language (e.g., female doctor: la médica). In terms of natural gender in Urdu, the biological gender (e.g., person, animal) denoted by a noun usually determines the gender of the noun (e.g., mother: mām; father: bāp). However, it is also true that in Urdu some words are not marked for gender and their gender must simply be learned (Schmidt, 2004). For example, the word for 'work' (kām) is masculine in Urdu.

\section{The present study}

Based on these language differences, and past findings, the primary objective of this research was to examine syntactic awareness in five- to six-year-old children who were monolingual (English) or bilingual (English/Spanish; English/Urdu). Syntactic awareness was assessed through the use of a grammaticality judgment test presented in English that asked children to judge the grammaticality of two types of language structures: word order (e.g., -SOV) and natural gender representation. As discussed shortly, all bilingual children were dominant in English, although receptive vocabulary ability (English and heritage language) varied within groups.

In terms of word order violations, we presented items that were agrammatical ("I bike rode the." instead of "I rode the bike."), or grammatically correct but asemantical. These latter sentences were those that included a semantic anomaly (i.e., "The table set the girl."). Although only the first type of sentence is a 'pure' word order violation, more recent research has suggested that sentences with a semantic anomaly also pose a word order violation (e.g., Barac \& Bialystok, 2012; Rainey, Davidson, \& Li-Grining, 2016). By presenting both types of sentences, we could more thoroughly assess monolingual and bilingual children's ability to detect these types of word order violations. In particular, there is some controversy about whether bilingual children are better than monolingual children at noting a semantic anomaly in a sentence (see Rainey et al., 2016, for a discussion).

Additionally, in the present study, we were interested in children's ability to detect natural gender problems in English. In half of the sentences, gender agreement was incorrect (e.g., "She is a good boy."), whereas in the remaining sentences the grammaticality of the sentence was ambiguous (e.g., "The boy slept in her own bed."). This allowed us to compare children's ability to detect purely ungrammatical gender constructions with ambiguous gender constructions without enough information at the sentence level to correctly co-index the antecedent with its ensuing pronoun.

Research questions were as follows: Do monolingual and bilingual children's performances differ on a grammaticality judgment test? Do potential monolingual 
and bilingual differences depend on their level of receptive vocabulary? Do potential bilingual differences depend on the syntactic structure being assessed (i.e., word order, gender representation)? How does cross-linguistic influence (e.g., similarities and differences between the syntactic structure of languages) affect bilingual children's ability to detect grammaticality correct and incorrect structures? Predictions were as follows:

1. Overall, it was predicted that bilingual advantages would emerge (i.e., more accurate performance on an English grammaticality judgment test) when bilingual children's English receptive vocabulary proficiency was at, or above, their age level, whereas disadvantages may be found for bilingual children who were not at their age level. This prediction was based on past studies that have shown that syntactic awareness skills, and bilingual advantages in particular, may require sufficient levels of language proficiency in young children (Cromdal, 1999; Davidson et al., 2010).

2. It was predicted that cross-linguistic influence would affect bilingual children's performance on an English grammaticality judgment test. Due to the overlap in -SOV word order between English and Spanish, bilingual English/ Spanish-speaking children were expected to exhibit greater accuracy in detecting grammatically correct and incorrect word order constructions (e.g., deviations from -SOV order in English) than monolingual English-speaking children. Differing predictions were made for bilingual English/Urdu-speaking children. On the one hand, bilingual English/Urdu-speaking children may exhibit lower accuracy than their peers due to the lack of word order overlap between English and Urdu. On the other hand, English/Urdu-speaking children may be more sensitive to word order violations than their peers due to differences in the word order structures of English and Urdu.

3. Due to the extent to which Spanish and Urdu use gender labels (determiner forms), as well as the fact that gender can be represented by natural and grammatical forms in Spanish and Urdu, but not English, it was also expected that bilingual children would be more sensitive to differences in the grammaticality of gender representations in English than monolingual English-speaking children. This hypothesis would be consistent with Davidson et al. (2010), who found that bilingual English/Urdu-speaking children showed greater awareness of grammatically correct and incorrect gender constructions than monolingual English-speaking children. They argued that this was due to the significant differences in the use of gender labeling of nouns and verbs in English and in Urdu.

4. Monolingual-bilingual differences may also be found in detecting word order violations. Specifically, in terms of agrammatical word order violations versus asemantical word order violations (i.e., those with a semantic anomaly), Davidson et al. (2010) found that bilingual children were better than monolingual children at detecting these types of violations. Others, however, found no significant differences between monolingual and bilingual children when children were asked to detect a semantic anomaly on a syntactic awareness task (Rainey et al., 2016), suggesting a similar lack of differences will be found in the present research.

5. However, evidence for Predictions 2, 3, and 4 were expected to be dependent upon children's receptive vocabulary ability in English. A bilingual advantage 
(i.e., greater accuracy in bilinguals) was only expected to be found when bilingual children were at or above their age level in receptive vocabulary ability for the sample, but was not expected when they were below their age level. Children with greater receptive vocabulary ability were also expected to be better at explaining their grammaticality judgments based on grammatical knowledge and not simply on the content of the sentence.

6. Finally, monolingual-bilingual differences were more readily expected when children were asked to judge the grammaticality of INCORRECT sentences than grammatically CORRECT sentences because past research has found fewer differences between monolingual and bilingual children when they were asked to identify grammatically correct constructions (Bialystok, 1981, 1986; Davidson et al., 2010). According to Davidson et al., this effect might be due to differences in the level of attentional control and knowledge analysis required to judge grammatically correct versus incorrect sentences, as identifying grammatically incorrect sentences demands more of these skills.

\section{Methods}

\section{Participants}

The total sample of participants included 121 children: 62 monolingual Englishspeaking children $\left(M_{\text {age }}=6 ; 1\right.$, range: 5;7-6;2), 35 bilingual children who spoke English and Spanish $\left(M_{\text {age }}=6 ; 0\right.$, range: 5;6-6;1), and 24 bilingual children who spoke English and Urdu $\left(M_{\text {age }}=6 ; 0\right.$, range: 5;7-6;1). The results of a one-way analysis of variance (ANOVA) showed that there were no significant differences in age between language groups $(F(2,118)=2.4, p=.16)$ (see Table 1 ). Children between five and six years of age were assessed because studies have shown that sensitivity to grammatically correct and incorrect syntactic structures is enhanced when children are exposed to both languages prior to age nine (Jia \& Fuse, 2007). Additionally, formal reading and writing instruction had just begun for the children, all of whom were in kindergarten. It has been suggested that, once formal schooling in English has been underway for a year or more (i.e., by the end of first grade), bilingual children often rapidly lose proficiency in their heritage language (Leikin, Schwartz, \& Share, 2010). Thus, the impact of their heritage language on syntactic awareness may be lessened with additional years of formal schooling.

Children were recruited from schools located in lower-middle-class neighborhoods in a large urban city and its neighboring suburbs. English was the sole language of instruction at their schools. However, bilingual English/Spanish-speaking children were exposed to some cultural activities at their schools that were conducted in Spanish, such as holiday songs and dance. For bilingual English/Urdu-speaking children, instruction in other languages (e.g., Arabic) was offered in their schools. However, these classes were not available to five- and six-year-old children. All children who were enrolled in the current study were reported by their parents to have been born in the United States.

Additional information was gathered about bilingual children through parent reports, including the estimated age at which the child learned English and his or her heritage language, and the circumstances that the child used English or their heritage language (e.g., with siblings). All parent forms were provided in English and the child's heritage language (Spanish, Urdu). 
Table 1. Parent-reported characteristics of monolingual and bilingual children

\begin{tabular}{lclll}
\hline & $\begin{array}{c}\text { Low } \\
\text { PPVT-III } \\
\text { English }\end{array}$ & $\begin{array}{c}\text { Middle } \\
\text { PPVT-III } \\
\text { English }\end{array}$ & $\begin{array}{c}\text { High } \\
\text { PPVT-III } \\
\text { English }\end{array}$ & $\begin{array}{c}\text { Overall } \\
\text { language } \\
\text { groups }\end{array}$ \\
\hline Sample size & 9 & 26 & 27 & 62 \\
\hline Monolingual & 6 & 18 & 11 & 35 \\
\hline Bilingual English/Spanish & 5 & 14 & 5 & 24 \\
\hline Bilingual English/Urdu & & & & \\
\hline Age & $5 ; 8(5 ; 7-5 ; 10)$ & $5 ; 10(5 ; 8-5 ; 11)$ & $6 ; 1(5 ; 9-6 ; 2)$ & $6 ; 1(5 ; 7-6 ; 2)$ \\
\hline Monolingual & $5 ; 6(5 ; 6-5 ; 9)$ & $5 ; 10(5 ; 8-6 ; 0)$ & $6 ; 1(5 ; 9-6 ; 1)$ & $6 ; 0(5 ; 6-6 ; 1)$ \\
\hline Bilingual English/Spanish & $5 ; 8(5 ; 7-5 ; 10)$ & $5 ; 11(5 ; 9-6 ; 1)$ & $6 ; 0(5 ; 11-6 ; 1)$ & $6 ; 0(5 ; 7-6 ; 1)$ \\
\hline Bilingual English/Urdu & & & & \\
\hline English as first language & $0 \%$ & $17 \%$ & $28 \%$ & $15 \%$ \\
\hline Bilingual English/Spanish & $0 \%$ & $50 \%$ & $100 \%$ & $50 \%$ \\
\hline Bilingual English/Urdu & $0 \%$ & & $100 \%$ & $100 \%$ \\
\hline English language used with siblings & & $100 \%$ & $100 \%$ \\
\hline Bilingual English/Spanish & $100 \%$ & $100 \%$ & $100 \%$ & \\
\hline Bilingual English/Urdu & $100 \%$ & & & \\
\hline
\end{tabular}

Notes. ${ }^{a}$ In bilingual children, percent reflects the extent to which parents estimated that English was used more often between siblings than the children's heritage language. Age is provided in years;months.

Data from three monolingual English-speaking children, two bilingual English/ Spanish-speaking children, and four bilingual English/Urdu-speaking children were not used because they were absent on one of the days of testing. Data from one monolingual child, three English/Spanish-speaking children, and one English/ Urdu-speaking child were also eliminated because their responses showed no discrimination between grammatically correct and incorrect sentences. Additionally, data from two bilingual English/Spanish-speaking children and one English/ Urdu-speaking child were not used because their parents did not fill out a parent report on their child's language development. Final sample sizes reflect these eliminations.

\section{Materials and procedure}

\section{Receptive vocabulary}

Receptive vocabulary was assessed in English for monolingual and bilingual (E/S, E/U) children using the Peabody Picture Vocabulary Test-III Form A (PPVT-III; Dunn \& Dunn, 1997). For this assessment, children have to identify the picture that matches with a given word from an array of four pictures per plate. The PPVT-III has a high internal consistency ( $\alpha=.92$ to .98$)$, good construct validity with verbal ability measures (WISC-III Verbal IQ, $r=.91$ ), and is able to detect developmental growth in vocabulary including nouns, verbs, and adjectives of increasing difficulty. Bilingual children's receptive vocabulary knowledge was also assessed in their heritage language using translated versions of the PPVT-III Form B. These versions were 
translated and back-translated by native speakers of the heritage language who were also fluent speakers of English. To our knowledge, there are no standardized receptive vocabulary measures in Urdu. However, translated versions of the PPVT-III Form B in Urdu have been used previously in published research (Davidson et al., 2010; Davidson \& Tell, 2005). Because we administered the PPVT-III in English and in Urdu, we also presented a translated version in Spanish for consistency across bilingual groups. To gauge the validity of the translated Spanish PPVT-III Form B, $40 \%$ of English/Spanish bilingual children were also administered the Test de Vocabulario en Imágenes Peabody (TVIP; Dunn, Lugo, Padilla, \& Dunn, 1986). A paired samples $t$-test showed no differences in English/Spanish bilingual children's receptive vocabulary knowledge across both measures $(t(13)=1.6, p=.18)$.

\section{Grammaticality judgment test of syntactic awareness}

In the present research, all children completed a grammaticality judgment test in English, and only English. A grammaticality judgment test was administered in lieu of other measures of syntactic awareness (e.g., oral cloze task, replication of errors task) for several reasons. First, most young children can provide a response on this type of task because such a response requires only a low level of attentional control. However, a more fine-tuned analysis of children's syntactic awareness abilities can also be obtained through the use of this test by asking children to explain their responses. In doing so, one can tap into their level of knowledge analysis (i.e., syntactic knowledge). Additionally, the grammaticality judgment test is beneficial because it allows one to assess children's awareness of a range of grammatical constructions.

The grammaticality judgment test included 40 sentences in English, 20 correct and 20 incorrect sentences randomly dispersed. Two different grammatical structures (word order, gender) were assessed. Table 2 shows examples of grammatically correct and incorrect examples for each language construction in English. As shown in Table 2, word order violations could take one of two forms. They could be completely agrammatical (e.g., "He to school walked."), or they could be asemantical with a word order violation leading to a semantic anomaly (e.g., "The TV watched the children."). Half of the word order violations were of the first type, and the remaining half were of the second. Gender violations also took one of two forms. Half resulted in incorrect gender agreement (e.g., "He is a mean girl."), whereas the remaining half produced an ambiguous gender agreement (e.g., "The boy played with her friends."). For additional examples see Table 2.

Twenty sentences were presented per construction, or 10 grammatically correct and 10 grammatically incorrect sentences of the types noted above. Thus, the grammaticality judgment task resulted in six total scores: Word Order-Correct, Word Order-Incorrect (Agrammatical), Word Order-Incorrect (Asemantical), GenderCorrect, Gender-Incorrect (Incorrect Agreement), and Gender-Incorrect (Ambiguous Agreement). Analogous to Davidson et al. (2010), children were told: "I'm going to read several sentences to you and I would like for you to tell me if each sentence sounds ok." If a child said "No, it didn't sound ok" or "You said it wrong", they were asked: "Tell me if you can, what is wrong with the way I said the sentence."

All children completed study measures across two 25-minute testing sessions conducted on separate, non-sequential days. Monolingual children completed the PPVT-III Form A and half of the grammaticality judgment task in the first session, with the order of administration counterbalanced. Monolingual children completed the remaining half of the grammaticality judgment task in the second session. 
Table 2. Examples of grammatically correct and incorrect English structures presented on the grammaticality judgment test

\begin{tabular}{|c|c|c|}
\hline Structure & Correct & Incorrect \\
\hline \multirow[t]{4}{*}{ Word order } & The rabbit ate a carrot. & The bike rode the. (agrammatical) \\
\hline & The teacher read the book. & He to school walked. (agrammatical) \\
\hline & The woman watered the lawn. & The TV watched the children. (asemantical) \\
\hline & The butterfly flew away. & The dinner ate the kid. (asemantical) \\
\hline \multirow[t]{4}{*}{ Gender } & The boy rode his bike. & He is a mean girl. (incorrect agreement) \\
\hline & She is a mean girl. & She is a good boy. (incorrect agreement) \\
\hline & The boy lost his homework. & The boy played with her friends. (ambiguous agreement) \\
\hline & The girl forgot her umbrella. & $\begin{array}{l}\text { The girl played with his friends. (ambiguous } \\
\text { agreement) }\end{array}$ \\
\hline
\end{tabular}

Notes. See text for more detailed explanation of incorrect grammatical constructions. As shown, asemantical constructions resulted in a semantic anomaly.

Bilingual children completed one receptive vocabulary measure in each session along with one half of the grammaticality judgment task. The order of PPVT-III presentation was counterbalanced in bilingual children (i.e., half were tested in English first and half were tested in Spanish/Urdu first). As previously noted, the grammaticality judgment task was only administered in English.

\section{Results}

\section{Preliminary analyses}

Data were first checked for missing values, outliers, and normality of distributions to ensure the suitability of inferential procedures (e.g., histogram, Levene's test; Tabachnick \& Fidell, 2007). Homogeneity of variance results (Levene's tests) showed no significant differences between language groups across the dependent variables $(F(8,112) \leq 1.9, p>.05)$. We did find that scores on the grammatically correct sentences were moderately positive skewed, but no advantage for using transformed scores over raw scores was obtained. Note that the pattern of significant findings did not change when receptive vocabulary proficiency in bilingual children was examined as a combined score (i.e., English and heritage language scores) and used as a covariate when assessing their performance on the grammaticality judgment test. Although the Urdu version of the PPVT-III has been used previously in published research (Davidson et al., 2010; Davidson \& Tell, 2005), raw scores on the PPVT were used in all subsequent analyses because the Urdu translation of the PPVT-III has not been standardized.

\section{Receptive vocabulary, parent reports, and language dominance}

Children's receptive vocabulary scores from the PPVT-III in English (Form A) and their heritage language (Form B for E/S and E/U; TVIP for E/S) are shown in Table 3. A one-way ANOVA found that English receptive vocabulary scores were not significantly different between language groups $(F(2,118)=2.87, p=.10)$. Additionally, 
Table 3. Receptive vocabulary of monolingual English-speaking and bilingual English/Spanish and English/Urdu-speaking children

\begin{tabular}{|c|c|c|c|c|}
\hline & $\begin{array}{l}\text { Low } \\
\text { PPVT-III } \\
\text { English }\end{array}$ & $\begin{array}{l}\text { Middle } \\
\text { PPVT-III } \\
\text { English }\end{array}$ & $\begin{array}{l}\text { High } \\
\text { PPVT-III } \\
\text { English }\end{array}$ & $\begin{array}{l}\text { Overall } \\
\text { PPVT-III } \\
\text { groups }\end{array}$ \\
\hline \multicolumn{5}{|l|}{ Monolingual $(n=62)$} \\
\hline PPVT-III English & $46.67(5.40)$ & $61.27(4.11)$ & $69.31(2.18)$ & $59.08(3.89)$ \\
\hline \multicolumn{5}{|c|}{ Bilingual English/Spanish $(n=35)$} \\
\hline PPVT-III English ${ }^{a}$ & $47.56(6.15)$ & $60.10(2.42)$ & $69.00(0.82)$ & $58.88(3.13)$ \\
\hline PPVT-III other ${ }^{a}$ & $40.67(7.60)$ & $41.24(4.89)$ & $49.44(3.21)$ & $43.78(5.23)$ \\
\hline TVIP & $44.30(8.10)$ & $45.81(6.01)$ & $48.20(5.98)$ & $46.10(6.69)$ \\
\hline \multicolumn{5}{|c|}{ Bilingual English/Urdu $(n=24)$} \\
\hline PPVT-III English ${ }^{a}$ & $51.17(4.22)$ & $63.93(2.26)$ & $68.00(0.98)$ & $61.03(2.49)$ \\
\hline PPVT-III other ${ }^{a}$ & $43.00(2.97)$ & $49.13(4.50)$ & $51.00(2.12)$ & $47.71(3.19)$ \\
\hline
\end{tabular}

Notes. ${ }^{\text {a }}$ PPVT-III Form A was administered to all children in English. PPVT-III Form B was administered in the child's heritage language, Spanish, or Urdu (see text for explanation). Standard deviations are in parentheses.

paired samples $t$-tests were used to determine bilingual children's language dominance by comparing receptive vocabulary scores in English (PPVT-III Form A) and their heritage language (PPVT-III Form B, TVIP). These analyses found that all children were dominant in English, with English receptive vocabulary scores higher than their heritage language receptive vocabulary scores on the PPVT-III $(t(34)=6.88 p<.0001$; $t(23)=4.21, p<.0001$, English/Spanish and English/Urdu, respectively). Based on an additional paired samples $t$-test, further support was found for English language dominance for English/Spanish bilinguals when receptive vocabulary scores for PPVT-III Form A and the TVIP were compared $(t(13)=3.10, p<.01)$. Individual inspection of bilingual children's receptive vocabulary scores also verified that all bilingual children obtained higher scores on English receptive vocabulary than their heritage language receptive vocabulary.

The majority of the children had raw scores on the PPVT Form A within the 56-67 range (about $48 \%$ overall), which was at their age level (see Table 3 ). Across language groups, $16 \%$ of the children scored within the $41-55$ range and $36 \%$ children scored within the $68-76$ range. No children scored above 76 on the PPVT Form A. Thus, we designated three groups of children based on these results: children in the lowest range (41-55) on the PPVT, children in the middle or average range (56-67), and children at the highest range for our sample (68-76). This designation took into account the percentage of children falling within each group, across all language groups. It also was based on the fact that no child scored a 55 or a 67 on the PPVT, suggesting that these were good breaking points between groups. This allowed us to assess syntactic awareness abilities within and between each of these receptive vocabulary ranges.

Although no significant differences were found between language groups in terms of age, we were interested in whether significant differences existed between groups within each PPVT (English) range and within groups across each PPVT range (see Table 1). The only finding was that bilingual English/Spanish-speaking children in the lowest 
PPVT (English) group were younger than bilingual English/Spanish-speaking children in the highest PPVT (English) group $(t(15)=2.61, p<.02)$, but not the middle group $(t(22)=1.3, p=.19)$. (see Table 1$)$.

Information about bilingual children's language use, such as whether or not English or their heritage language was their first language, is provided in Table 1. Parents of bilingual English/Spanish-speaking children were more likely to report that their children learned Spanish before English, whereas only $50 \%$ of the parents of bilingual English/Urdu-speaking children reported that their children learned Urdu before English (see Table 1). Additional information obtained from the parents revealed that bilingual children were more likely to use English than their heritage language with their siblings.

\section{Grammaticality judgment test of syntactic awareness}

Tables 4 and 5 present overall mean proportion correct in identifying grammatically correct and incorrect constructions by language group and PPVT-range. Using total number of correct scores, a mixed-model ANOVA was conducted on the judgment of grammatically correct and incorrect sentences in monolingual and bilingual children. Between-subjects variables were Language Group (monolingual-English, bilingual English/Spanish, bilingual English/Urdu) and English PPVT Range (41-55 or 'Low Range'; 56-67 or 'Middle Range'; 68-76 or 'High Range'). Within-subjects variables included Grammaticality (Correct Constructions, Incorrect Constructions) and Language Structure (Word Order, Gender).

A number of significant findings were revealed. Main effects included Grammaticality $\left(F(1,112)=48.67, p=.0001, \eta_{p}^{2}=.30\right)$, Language Structure $(F(4,112)=2.79, p=.03$, $\left.\eta_{p}^{2}=.09\right)$, and PPVT-Range $\left(F(2,112)=24.35, p=.0001, \eta_{p}^{2}=.30\right)$. Additionally, a significant Grammaticality $\times$ Language Structure $\times$ PPVT-Range three-way interaction $\left(F(2,112)=3.16, p=.05, \eta_{p}^{2}=.15\right)$ was found, as were several two-way interactions: a Grammaticality $\times$ Language Structure $\left(F(2,112)=3.91, p=.05, \eta_{p}^{2}=.03\right)$, a Language Structure $\times$ PPVT-Range $\left(F(2,112)=3.16, p=.05, \eta_{p}^{2}=.05\right)$, and Language Group $\times$ PPVT-Range $\left(F(1,112)=2.79, p=.03, \eta_{p}^{2}=.09\right)$. The Language Group $\times$ Grammaticality interaction approached significance $\left(F(2,112)=2.00, p=.06, \eta_{p}^{2}=.05\right)$. In order to avoid Type I error, the Bonferroni correction method was used when examining these results. This method requires that the alpha level take into account the number of comparisons made and adjust the alpha accordingly (e.g., .05/4 =.01, .05/3=.02). Unless otherwise noted, all follow-up results can be seen in Tables 4 and 5 .

Regarding the three-way interaction, we conducted repeated measures ANOVAs on each PPVT range. In the low and middle PPVT ranges, main effects of Grammaticality $\left(F(1,112) \geq 34.98, p \leq .0001, \eta_{p}^{2} \geq .44\right)$ and Language Structure ( $F$ $(1,112) \geq 23.33, p \leq .0001, \bar{\eta}_{p}^{2} \geq .28$ ) were found (see Tables 4 and 5 ). However, using the Bonferroni correction, the Grammaticality $\times$ Language Structure interaction was not significant $\left(F(1,112) \leq 4.83, p \geq .03, \eta_{p}^{2} \leq .08\right)$. In the low and middle ranges, all children were better at identifying correct grammatical constructions than incorrect constructions $(t(23-60) \geq 4.83, p \leq .0001)$. They were also better at identifying correct and incorrect word order than gender constructions $(t(23-60) \geq 5.19, p \leq .0001)$. In contrast, in the high PPVT range there was a significant interaction between Grammaticality and Language Structure $\left(F(1,112) \geq 12.09, p \leq .001, \eta_{p}^{2} \geq .26\right)$. For children in this range, there were no significant difference in identifying correct and incorrect word order constructions $(t(35)=0.0001, p=1.00)$. However, children in the 
Table 4. Monolingual (English) and bilingual (English/Spanish; English/Urdu) children's mean grammaticality judgment scores (proportion correct) by receptive vocabulary range for sentences with grammatically correct word order and gender constructions

\begin{tabular}{|c|c|c|c|c|}
\hline Low PPVT-III Range (41-55) & $\begin{array}{c}M \\
(n=9)\end{array}$ & $\begin{array}{c}E / S \\
(n=6)\end{array}$ & $\begin{array}{c}E / U \\
(n=5)\end{array}$ & $\begin{array}{l}\text { Overall } \\
(n=20)\end{array}$ \\
\hline Word order & $.90(.09)$ & $.75(.20)$ & $.81(.10)$ & $.82(.13)$ \\
\hline Gender & $.73(.13)$ & $.63(.17)$ & $.66(.14)$ & $.67(.15)$ \\
\hline Middle PPVT-III Range (56-67) & $\begin{array}{c}M \\
(n=26)\end{array}$ & $\begin{array}{l}\mathrm{E} / \mathrm{S} \\
(n=18)\end{array}$ & $\begin{array}{l}\mathrm{E} / \mathrm{U} \\
(n=14)\end{array}$ & $\begin{array}{l}\text { Overall } \\
\qquad(n=58)\end{array}$ \\
\hline Word order & $.89(.13)$ & $.88(.11)$ & $.84(.12)$ & $.87(.12)$ \\
\hline Gender & $.83(.18)$ & $.82(.17)$ & $.71(.19)$ & $.79(.18)$ \\
\hline High PPVT-III Range (68-76) & $\begin{array}{c}M \\
(n=27)\end{array}$ & $\begin{array}{l}\mathrm{E} / \mathrm{S} \\
(n=11)\end{array}$ & $\begin{array}{l}\mathrm{E} / \mathrm{U} \\
(n=5)\end{array}$ & $\begin{array}{l}\text { Overall } \\
\qquad(n=43)\end{array}$ \\
\hline Word order & $.89(.17)$ & $.92(.10)$ & $.90(.10)$ & $.90(.12)$ \\
\hline Gender & $.87(.15)$ & $.96(.05)$ & $.83(.15)$ & $.89(.12)$ \\
\hline
\end{tabular}

Notes. $\mathrm{M}=$ monolingual, $\mathrm{E} / \mathrm{S}=$ bilingual English/Spanish, $\mathrm{E} / \mathrm{U}=$ bilingual English/Urdu; all sentences presented in English, with mean proportion correct reflecting children's ability to detect GRAMMATICALLY CORRECT sentences. Standard deviations are in parentheses.

high range were better at identifying correct gender constructions than incorrect gender constructions $(t(35)=3.35, p=.002)$. Additionally, for correct constructions, no significant differences were found in their ability to identify correct word order versus gender constructions $(t(35)=-0.07, p=.95)$ (see Table 4$)$. In contrast, children in the high range were significantly better at identifying incorrect word order constructions than incorrect gender constructions $(t(35)=-5.33, p=.0001)$ (see Table 5).

In terms of the Language Group $\times$ PPVT-Range two-way interaction, one-way ANOVAs showed the main effect of Language Group for overall accuracy was not significant (low: $F(2,21)=1.78, p=.19, \eta_{p}^{2}=.15$; middle: $F(2,58)=2.98, p=.06$, $\eta_{p}^{2}=.09$; and high: $\left.F(2,33)=3.03, p=.06, \eta_{p}^{2}=.16\right)$.

Given the importance of language group as a variable, we explored the Language Group $\times$ Grammaticality interaction that approached significance. Follow-up independent samples $t$-tests showed that monolingual children were better at detecting correct grammatical constructions than bilingual English/Urdu-speaking children $(t(84)=2.74, p=.01)$, but they did not differ from bilingual English/ Spanish-speaking children $(t(84)=1.66, p=.10)$. The reverse pattern was found for incorrect constructions: monolingual children did not differ from bilingual English/ Urdu-speaking children $(t(95)=1.45, p=.15)$, but they were better than bilingual English/Spanish-speaking children $(t(95)=2.71, p=.01)$ (see Figure 1 ).

In addition to the overall analyses, we were also interested in children's ability to detect specific types of incorrect word order constructions. Recall that there were two types of incorrect word order constructions: an agrammatical word order (e.g., "I bike rode the.") and a word order construction that led to a semantic anomaly (e.g., "The food ate the boy."). A mixed-model ANOVA was conducted on this data. The between-subjects variables were Language Group (monolingual-English, bilingual English/Spanish, bilingual English/Urdu) and English PPVT Range (41-55 or 'Low Range'; 56-67 or 'Middle Range'; 68-76 or 'High Range'), and the within-subjects 
Table 5. Monolingual (English) and bilingual (English/Spanish; English/Urdu) children's mean grammaticality judgment scores (proportion correct) by receptive vocabulary range for sentences with grammatically incorrect word order and gender constructions

\begin{tabular}{|c|c|c|c|c|}
\hline Low PPVT-III Range (41-55) & $\begin{array}{c}M \\
(n=9)\end{array}$ & $\begin{array}{c}E / S \\
(n=6)\end{array}$ & $\begin{array}{c}\mathrm{E} / \mathrm{U} \\
(n=5)\end{array}$ & Mean total \\
\hline \multicolumn{5}{|l|}{ Word order } \\
\hline Agrammatical & $.47(.37)$ & $.34(.25)$ & $.57(18)$ & $.46(.27)$ \\
\hline Asemantical & $.40(.36)$ & $.53(.29)$ & $.69(.16)$ & $.54(.27)$ \\
\hline \multicolumn{5}{|l|}{ Gender } \\
\hline Incorrect Agreement & $.44(.23)$ & $.39(.17)$ & $.50(.17)$ & $.44(.19)$ \\
\hline Ambiguous Agreement & $.42(34)$ & $.32(.12)$ & $.25(.20)$ & $.33(.22)$ \\
\hline Middle PPVT-III Range (56-67) & $\begin{array}{c}M \\
(n=26)\end{array}$ & $\begin{array}{l}\mathrm{E} / \mathrm{S} \\
(n=18)\end{array}$ & $\begin{array}{l}\mathrm{E} / \mathrm{U} \\
(n=14)\end{array}$ & Mean total \\
\hline \multicolumn{5}{|l|}{ Word order } \\
\hline Agrammatical & $.71(.33)$ & $.54(.36)$ & $.67(.31)$ & $.64(.33)$ \\
\hline Asemantical & $.83(.28)$ & $.61(.41)$ & $.73(.33)$ & $.72(.34)$ \\
\hline \multicolumn{5}{|l|}{ Gender } \\
\hline Incorrect Agreement & $.70(.33)$ & $.63(.30)$ & $.61(.32)$ & $.65(.32)$ \\
\hline Ambiguous Agreement & $.50(.39)$ & $.31(.20)$ & $.29(.27)$ & $.37(.29)$ \\
\hline High PPVT-III Range (68-76) & $\begin{array}{c}M \\
(n=27)\end{array}$ & $\begin{array}{l}\mathrm{E} / \mathrm{S} \\
(n=11)\end{array}$ & $\begin{array}{l}E / U \\
(n=5)\end{array}$ & Mean total \\
\hline \multicolumn{5}{|l|}{ Word order } \\
\hline Agrammatical & $.88(.17)$ & $.93(.10)$ & $1.00(.00)$ & $.94(.09)$ \\
\hline Asemantical & $.87(.17)$ & $.97(.08)$ & $.93(.12)$ & $.92(.12)$ \\
\hline \multicolumn{5}{|l|}{ Gender } \\
\hline Incorrect agreement & $.81(.23)$ & $1.00(.00)$ & $.89(.19)$ & $.90(.14)$ \\
\hline Ambiguous agreement & $.45(.31)$ & $.54(.25)$ & $.67(.29)$ & $.55(.28)$ \\
\hline
\end{tabular}

Notes. $\mathrm{M}=$ monolingual, $\mathrm{E} / \mathrm{S}=$ bilingual English/Spanish, $\mathrm{E} / \mathrm{U}=$ bilingual English/Urdu; all sentences presented in English, with mean proportion correct reflecting children's ability to detect GRAMMATICALLY INCORRECT sentences. Standard deviations are in parentheses.

variable was type of incorrect word order construction (agrammatical, asemantical). The results of this analysis revealed a main effect of PPVT-Range $(F(2,112)=13.33$, $p=.0001, \eta_{p}^{2}=.19$ ). Follow-up tests using Bonferroni correction revealed that children with higher PPVT scores were better at identifying the incorrect constructions than children with lower PPVT scores $(t(58-95) \geq-2.83, p \leq .006)$. Children in the high PPVT range were accurate in detecting incorrect word order constructions $90 \%$ of the time, whereas children in the middle range were accurate $70 \%$ of the time, and children in the low range were only accurate $49 \%$ of the time. A main effect of Word Order Structure approached significance $\left(F(1,112)=3.57, p=.06, \eta_{p}^{2}=.03\right)$ : children identified asemantical constructions (i.e., constructions with a semantic anomaly) $75 \%$ of the time, whereas they identified agrammatical word order constructions only $68 \%$ of the time. 


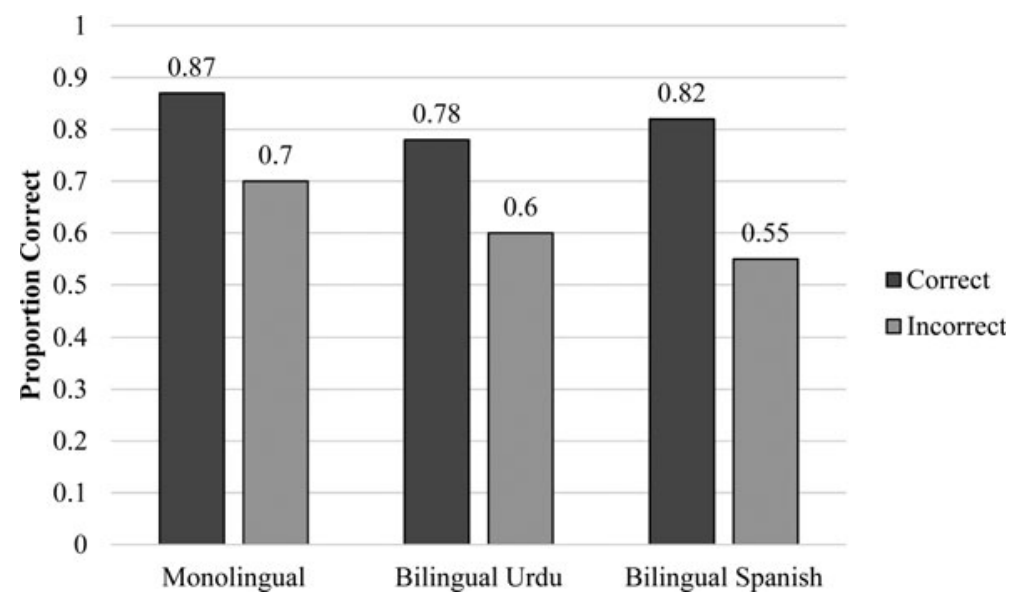

Figure 1. Children's grammaticality judgment scores (proportion correct) by language group (Monolingual, Bilingual English/Urdu, Bilingual English/Spanish).

Additionally, we were interested in children's ability to detect gender constructions with incorrect agreement versus ambiguous agreement. A mixed-model ANOVA was conducted on this data. The between-subjects variables were Language Group (monolingual-English, bilingual English/Spanish, bilingual English/Urdu) and English PPVT Range (41-55 or 'Low Range'; 56-67 or 'Middle Range'; $68-76$ or 'High Range'), and the within-subjects variable was type of incorrect Gender Representation Type (i.e., incorrect agreement, ambiguous agreement). The results of this analysis revealed a significant main effect of Gender Representation Type $\left(F(1,112)=60.62, p=.0001, \eta_{p}^{2}=.35\right)$ and PPVT-Range $(F(2,112)=9.10, p=.0001$, $\left.\eta_{p}^{2}=.14\right)$, as well as a significant Gender Representation $\times$ PPVT-Range interaction $\left(F(2,112)=4.00, p=.02, \eta_{p}^{2}=.07\right)$. Follow-up independent samples $t$-tests with Bonferroni correction revealed that, as the PPVT range increased, children were better at identifying incorrect gender agreement constructions $(t(58-95)>-3.21$, $p \leq .002)$. In contrast, no significant differences were found between PPVT ranges in terms of identifying ambiguous gender constructions $(t(58-95) \leq-2.31, p \geq .03)$.

\section{Assessing predictors of syntactic awareness}

Linear multiple regression analyses were conducted to determine how bilingual language group (English/Spanish, English/Urdu), receptive vocabulary in English (PPVT A), and receptive vocabulary in the heritage language (PPVT B) predicted bilingual children's performance on the grammaticality judgment test. Also examined was whether receptive vocabulary ability (PPVT A) predicted monolingual children's performance on the grammaticality judgment test. Because age and PPVT scores were correlated with each other, and therefore multicollinearity existed between them, we did not include age as a predictor in the model. More specifically, when running models with and without age, we found that the model with age accounted for less variance. In doing these analyses, we also explored the degree of multicollinearity using the variance inflation factor (VIF). Our VIF exceeded 4, which indicated problems with multicollinearity if the predictor age was left in the 
equation. Finally, age was removed from the model because we used PPVT raw scores instead of standardized scores, the latter of which would have adjusted for age differences. We used raw scores because standardized scores are not available for the Urdu version of the PPVT.

\section{Grammatically correct constructions}

For bilinguals, the overall model (Language Group, PPVT A, PPVT B) accounted for a significant amount of variance in children's ability to identify correct word order $\left(F(3,55)=5.73, p=.002, R^{2}=.24\right)$ and gender constructions $(F(3,55)=4.65, p=.006$, $R^{2}=.20$ ). For word order constructions, English receptive vocabulary (PPVT A) was the only significant predictor of bilingual children's ability to detect correct word order constructions $(\beta=0.42, t(54)=3.47, p=.001)$. Similarly, PPVT A was a significant predictor of children's ability to detect correct gender constructions $(\beta=$ $0.42, t(54)=3.47, p=.001)$. However, among monolingual children, PPVT A scores did not significantly predict their detection of grammatically correct word order $\left(F(1,60)=0.26, p=.61, R^{2}=.004, \beta=-0.07\right)$ or gender constructions $(F(1,60)=2.02$, $\left.p=.16, R^{2}=.01, \beta=0.08\right)$.

\section{Grammatically incorrect constructions}

Additional linear regression analyses were conducted on children's judgments of grammatically incorrect constructions. In bilingual children, the overall model, including language group, PPVT A, and PPVT B, accounted for a significant amount of variance in children's identification of incorrect gender constructions $(F(3,55)=$ $\left.3.70, p=.02, R^{2}=.17\right)$. More specifically, PPVT A was a significant predictor of bilingual children's ability to identify incorrect gender constructions $(\beta=0.39, t$ $(54)=3.14, p=.003)$. Additionally, analyses on word order constructions revealed that the overall model approached significance $\left(F(3,55)=2.39, p=.08, R^{2}=.12\right)$. No other significant findings were seen for bilinguals. For monolinguals, PPVT A significantly predicted their detection of grammatically incorrect word order $\left(F(1,60)=12.20, p=.0001, R^{2}=.18, \beta=0.41\right)$, but not incorrect gender constructions $\left(F(1,60)=0.37, p=.55, R^{2}=.01, \beta=0.08\right)$.

\section{Children's explanations of their answers}

When we asked children to explain why a sentence was grammatically correct or incorrect, very few could offer a reasonable explanation. Most simply said, “... because you said it right" or "... because you said it wrong", but could not elaborate on their statements. Some of the children in the highest receptive vocabulary range (i.e., about $20 \%$ of all of the children in the highest range) were more likely to refer to grammatical knowledge in explaining their judgments than children in the middle or lower ranges. Most of the children, however, did not explain their judgments by referring to their grammatical knowledge, regardless of receptive vocabulary ability or language group.

\section{Discussion}

The purpose of the present research was to examine monolingual (English) and bilingual (English/Spanish; English/Urdu) children's ability to detect grammatically 
correct and incorrect word order and gender constructions in English using a grammaticality judgment test. Understanding the early development of syntactic awareness, as measured by such tasks, is important because studies have documented positive relations between syntactic awareness and language and reading proficiency (e.g., Jia, Aaronson, \& Wu, 2002; Katz, 2004; Mokhtari \& Thompson, 2006). Past research, however, has shown inconsistent findings with regard to monolingualbilingual differences on measures of syntactic awareness. Some studies have shown bilingual advantages (e.g., Bialystok, 2007; Cromdal, 1999; Davidson et al., 2010), whereas other studies have shown bilingual advantages for only certain groups of bilingual children (i.e., highly proficient bilinguals: Davidson et al., 2017). In contrast, additional studies have shown that bilingual children perform more poorly than monolingual children (e.g., Da Fontoura \& Siegel, 1995; Lipka et al., 2005). A number of reasons have been postulated to explain these inconsistencies in findings, including the possibility that fewer monolingual-bilingual differences are found when bilingual children are tested in their dominant language and show sufficient levels of receptive vocabulary ability in that language (Davidson et al., 2010, 2017). The present study suggests that an even more complicated picture may exist.

In the current research, the grammaticality judgment test was administered in English because all bilingual children showed dominance in English (i.e., receptive vocabulary scores were better in English than in children's heritage language). This eliminated a potential confound seen in several past studies, or the comparison of monolingual and bilingual groups on a grammaticality judgment test in a language that bilingual children were not dominant in. However, across each of the language groups, receptive vocabulary scores in English (and in children's heritage language) were allowed to vary.

Therefore, our first research question concerned whether we would find differences between monolingual and bilingual children on the grammaticality judgement task, which was used as a measure of syntactic awareness. Additionally, we were interested in how receptive vocabulary range might interact with these findings. In terms of overall accuracy, few differences were found between the language groups. For example, although the language group $\times$ PPVT range interaction was significant, follow-up analyses revealed that the language groups did not differ in their overall accuracy on the grammaticality judgment task. These findings are in contrast to our first prediction suggesting that a bilingual advantage would be found, particularly in the highest receptive vocabulary range.

Instead, what we found was that bilingualism per se did not impact our results as much as receptive vocabulary range. That is, receptive vocabulary level interacted with performance across the language groups in a number of ways. First, in the low and middle PPVT ranges, all children were better at identifying correct and incorrect word order constructions than gender constructions. In contrast, in the high PPVT range, there was a significant interaction between grammaticality (correct versus incorrect) and language structure. Looking at the overall pattern, all children were more accurate at identifying word order constructions than gender constructions. However, in the highest PPVT range this difference was centered on incorrect constructions, as they were equally good at identifying correct word order and gender constructions.

These results suggest that, overall, children's ability to detect the grammaticality of gender constructions was more difficult than their ability to detect the grammaticality of word order constructions. It may be that word order violations are more central to 
syntactic awareness than violations of gender representation. This would be consistent with the distinction between episyntactic and metasyntactic judgments. As Gombert (1992, 1999) and others (Tunmer \& Grieve, 1984) have suggested, judgment of sentences as grammatical may be episyntactic in nature when that judgment is based simply on the dissonance of the utterance within the pragmatic or semantic context, rather than on conscious reflection about syntax per se. In other words, the children in our study may have been able to more readily detect grammatically correct and incorrect word order constructions simply because of the ease at which the information may have sounded dissonant to them. It may be that detecting the grammaticality of gender constructions requires more conscious reflection precisely because the word order in the sentence may be correct. As children become older, and their judgments become more metalinguistic in nature, these differences will be diminished. This would be an important question for future research.

Receptive vocabulary ability also impacted children's ability to correctly identify specific types of incorrect word order and gender constructions. Recall that we presented two types of grammatically incorrect word order and gender constructions. Word order constructions either could be incorrect by the misplacement of the subject, object, and verb (e.g., "He to school walked."), or could be incorrect because of a semantic anomaly (e.g., "The dinner ate the kid.") created by the word order in the sentence. Gender constructions could vary either by producing a violation in agreement (e.g., "She is a good boy.") or by producing an ambiguous gender representation (e.g., "The boy played with her friends."). In terms of word order constructions, children with higher receptive vocabulary scores were more accurate at identifying agrammatical and asemantical constructions compared to children with lower receptive vocabulary scores. In fact, at the highest receptive vocabulary range, children were accurate at detecting these incorrect word order constructions $90 \%$ of the time, whereas children at the lowest range were only accurate at detecting these incorrect word order constructions $49 \%$ of the time. The fact that we did not find differences between our language groups in detecting word order violations leading to a semantic anomaly is noteworthy as well. These results are consistent with studies that have shown that grammaticality judgment tasks with semantic anomalies, or tasks that require consistent engagement of the executive functioning system in order to detect that semantic anomaly, tend not to find a consistent bilingual advantage (see Barac \& Bialystok, 2012, for a discussion).

In terms of gender constructions, children in the highest receptive vocabulary range were the only group that was better at detecting incorrect gender agreement. In contrast, no significant differences were found between receptive vocabulary ranges in terms of identifying ambiguous gender constructions. Overall, children were better at detecting incorrect gender agreement than ambiguous gender agreement, which is not surprising given that the children may not have been reflecting on the sentence itself, but instead were considering the potential context the ambiguous sentence might have been in. For example, "The girl played with his friends." could be a perfectly fine sentence if additional information had been provided that allowed the child to correctly co-index the antecedent with its ensuing pronoun. This provides evidence that, when judging the grammaticality of a sentence, children may infer information about the sentence that is not presented. As Gombert $(1992,1999)$ suggests, when children move from an epilinguistic stage to a more metalinguistic one, they can focus their judgments on the sentence itself. 
The findings of our regression analyses lend partial support to the interplay between receptive vocabulary ability and syntactic awareness. For both groups of bilingual children, English receptive vocabulary abilities were a consistent predictor of grammaticality judgment test performance across grammatically correct and incorrect word order and gender constructions. However, receptive vocabulary ability in bilingual children's heritage language did not predict performance on the grammaticality judgment test, suggesting that the connection between receptive vocabulary ability and syntactic awareness ability may only exist within a language. In monolingual children, receptive vocabulary ability in English did not predict performance on correct grammatical constructions, but did predict the detection of grammatically incorrect word order constructions. These results suggest that receptive vocabulary ability in the language of testing may be more important for bilingual children than monolingual children.

In line with our last prediction, our findings indicate that, in general, children were more accurate in judging correct versus incorrect constructions. This pattern of performance is typical in syntactic awareness studies with young children and may be a consequence of the high levels of attentional control and knowledge analysis that are required by each form of syntactical construction (Davidson et al., 2010; Simard et al., 2013). In particular, identifying grammatically incorrect sentences should require more of these skills. Finally, most of the monolingual and bilingual children in our study could not articulate why a statement was grammatically incorrect. This finding is in line with past research that has shown that prior to age seven or eight, young children struggle with explaining grammaticality judgments by referring to grammatical knowledge (Galambos \& Goldin-Meadow, 1990). The fact that most of the children in our study were not able to explain their judgments using grammatical knowledge suggests that the children were more likely demonstrating epilinguistic than metalinguistic processing (Gaux \& Gombert, 1999; Gombert, 1999). With epilinguistic processes, detection of ungrammatical structures can happen if the child is confused by the dissonance of the sentence or when the child realizes that he or she does not understand the poorly formed utterance. However, once epilinguistic control is stable and efficient, metalinguistic awareness (i.e., the ability to consciously apply syntactic knowledge) becomes possible (see Gombert, 1999, for a discussion).

\section{Limitations and future directions}

Although we believe our results are compelling, several limitations should be noted. First, greater numbers of bilingual children in the highest and lowest range of receptive vocabulary ability could not be found, which will need to be addressed in future research. It will also be important to assess syntactic awareness abilities in bilingual children who show language dominance in their heritage language. Second, our data cannot determine whether enhanced vocabulary leads to better syntactic awareness or vice versa, although we believe it is clear from our findings that receptive vocabulary abilities and syntactic awareness are closely connected. An additional limitation is that we were not able to assess how the structures of the languages, and in particular structural overlap, might affect children's syntactic awareness because we had so few language group differences. It may be that future studies that focus only on monolingual and bilingual children with strong receptive vocabulary abilities might be better able to uncover how similarities and differences between the languages affect these types of grammatical judgments. Additional 
measures of language dominance may also be relevant for assessing language proficiency (i.e., differences in literacy skills such as reading and writing). Given the relatively young age of our children, and because reading and writing instruction had just begun for the children, we did not collect information about literacy. There is also the difficulty of measuring literacy abilities in languages where we do not have standardized proficiency measures (e.g., Urdu) readily available to us as researchers. Finally, input differences (i.e., exposure differences, cultural or extracurricular activities, etc.) may impact the development of children's syntactic awareness.

\section{Conclusion}

We believe that the present results add to a small, but growing body of literature suggesting that receptive language proficiency should be considered when examining monolingualbilingual differences on syntactic awareness measures. This study also increases our understanding of the relation between receptive vocabulary and grammatical judgments in young monolingual and bilingual children. Our results provide evidence that greater vocabulary proficiency in a language may be associated with children's epilinguistic awareness and adds to research findings showing that greater vocabulary proficiency is often linked with more efficient lexical and syntactic processing (Marchman et al., 2010). This may have important educational implications in terms of the need for developing children's early receptive language abilities.

Acknowledgements. We wish to thank the children, parents, teachers, and staff involved in this project for their generous cooperation. We would also like to thank Younus Baig for his assistance with Urdu language examples. Portions of this research were presented at the biennial meeting for the Society for Research in Child Development, 2011.

\section{References}

Ahmed, T., \& Alvi, S. (2002). English to Urdu machine translation system. Unpublished manuscript, University of Karachi, Pakistan.

Bachman, L. (1990). Fundamental considerations in language testing. Oxford University Press.

Bachman, L., \& Palmer, A. (1996). Language testing in practice. Oxford University Press.

Barac, R., \& Bialystok, E. (2012). Bilingual effects on cognitive and linguistic development: role of language, cultural background, and education. Child Development, 83, 413-22.

Bates, E., \& Goodman, J. C. (1997). On the inseparability of grammar and the lexicon: evidence from acquisition, aphasia, and real-time processing. Language and Cognitive Processes, 12, 507-84.

Bialystok, E. (1981). The role of conscious strategies in second language proficiency. Modern Language Journal, 65, 24-35.

Bialystok, E. (1986). Factors in the growth of linguistic awareness. Child Development, 57, 498-510.

Bialystok, E. (2001). Bilingualism in development: language, literacy \& cognition. New York: Cambridge University Press.

Bialystok, E. (2007). Cognitive effects of bilingualism: how linguistic experience leads to cognitive change. International Journal of Bilingual Education and Bilingualism, 10, 210-23.

Bialystok, E., \& Barac, R. (2013). Cognitive effects. In P. Li \& F. Grosjean (Eds.), The psycholinguistics of bilingualism (pp. 193-213). Malden, MA: Wiley-Blackwell.

Bialystok, E., Luk, G., Peets, K. F., \& Yang, S. (2010). Receptive vocabulary differences in monolingual and bilingual children. Bilingualism: Language and Cognition, 13, 525-31.

Cain, K. (2007). Syntactic awareness and reading ability: Is there any evidence for a special relationship? Applied Psycholinguistics, 28, 679-94.

Carlisle, J. F. (2003). Morphology matters in learning to read: a commentary. Reading Psychology, 24, 291-322.

Chomsky, N. (1995). The Minimalist Program. Cambridge, MA: MIT Press. 
Costa, A., Kovacic, D., Frank, J., \& Caramazza, A. (2003). On the autonomy of the grammatical gender systems of the two languages of a bilingual. Bilingualism: Language and Cognition, 6, 181-200.

Cromdal, J. (1999). Childhood bilingualism and metalinguistic skills: analysis and control in young Swedish-English bilinguals. Applied Psycholinguistics, 20, 1-20.

Da Fontoura, H., \& Siegel, L. (1995). Reading, syntactic, and working memory skills of bilingual Portuguese-English Canadian children. Reading and Writing: An Interdisciplinary Journal, 7, 139-53.

Davidson, D., Raschke, V. R., \& Pervez, J. (2010). Syntactic awareness in young monolingual and bilingual (Urdu-English) children. Cognitive Development, 25, 166-82.

Davidson, D., \& Tell, D. (2005). Monolingual and bilingual children's use of mutual exclusivity in naming whole objects. Journal of Experimental Child Psychology, 92, 25-45.

Davidson, D., Vanegas, S. B., Hilvert, E., \& Misiunaite, I. (2017). "I readed the book last week": the role of domininant language, receptive vocabulary and language structure on morphosyntactic awareness in monolingual and heritage language children. Bilingualism: Language and Cognition, 20, 1045-62.

Dunn, L. M., \& Dunn, L. M. (1997). Peabody Picture Vocabulary Test (3rd Edition). Circle Pines, MN: American Guidance Service.

Dunn, L. M., Lugo, D. E., Padilla, E. R., \& Dunn, L. M. (1986). Test de Vocabulario en Imágenes Peabody. Circle Pines, MN: American Guidance Service.

Erichsen, G. (2012). About.com Spanish Language. Cognate. Retrieved from <http://spanish.about.com/cs/ vocabulary/g/cognategloss.htm>.

Foursha-Stevenson, C., \& Nicoladis, E. (2011). Early emergence of syntactic awareness and cross-linguistic influence in bilingual children's judgments. International Journal of Bilingualism, 15, 521-34.

Galambos, S. J., \& Goldin-Meadow, S. (1990). The effects of learning two langauges on levels of metalinguistic awareness. Cognition, 34, 1-56.

Galambos, S. J., \& Hakuta, K. (1988). Subject-specific and task-specific characteristics of metalinguistic awareness in bilingual children. Applied Psycholinguistics, 9, 141-62.

Gathercole, V. C. M., \& Thomas, E. M. (2005). Minority language survival: input factors influencing the acquisition of Welsh. In J. Cohen, K. McAlister, K. Rolstad, \& J. MacSwan (Eds.), ISB4: Proceedings of the 4th International Symposium on Bilingualism (pp. 852-874). Somerville, MA: Cascadilla Press.

Gaux, C., \& Gombert, J. E. (1999). Implicit and explicit syntactic knowledge and reading in pre-adolescents. British Journal of Developmental Psychology, 17, 169-88.

Genesee, F., Nicoladis, E., \& Paradis, J. (1995). Language differentiation in early bilingual development. Journal of Child Language, 22, 611-31.

Gleitman, H., \& Gleitman, L. R. (1979). Language use and language judgment. In C. J. Fillmore, D. Kempler, \& W. S. Wang (Eds.), Individual differences in language ability and language behavior (pp. 103-26). New York: Academic Press.

Gombert, J. (1992). Metalinguistic development. University of Chicago Press.

Gombert, J. (1999). Metalinguistic development in first language acquisition. In L. Van Lier \& D. Corson (Eds.), Encyclopedia of language and education (Vol. 6, pp. 43-51). Boston, MA: Kluwer Academic Publishers.

Gombert, J. (2003). Implicit and explicit learning to read: implication as for subtypes of dyslexia. Current Psychology Letters: Behaviour, Brain \& Cognition, 10. Retrieved from <https://journals.openedition.org/ $\mathrm{cpl} / 202>$.

Goswami, U., Ziegler, J. C., \& Richardson, U. (2005). The effects of spelling consistency on phonological awareness: a comparison of English and German. Journal of Experimental Child Psychology, 92, 345-65.

Grosjean, F. (2013). Bilingualism: a short introduction. In F. Grosjean \& L. Ping, The psycholinguistics of bilingualism (pp. 5-25). West Sussex: Wiley-Blackwell.

Grosjean, F. (2015). Bicultural bilinguals. International Journal of Bilingualism, 19, 572-86.

Grosjean, F., \& Li, P. (2013). The psycholinguistics of bilingualism. West Sussex: Wiley-Blackwell.

Guo, Y., Roehrig, A. D., \& Williams, R. S. (2011). The relation of morphological awareness and syntactic awareness to adults' reading comprehension: Is vocabulary knowledge a mediating variable? Journal of Literacy Research, 43, 159-83.

Hirsch-Pasek, K., Gleitman, L. R., \& Gleitman, H. (1978). What did the brain say to the mind? A study of the detection and report of ambiguity by young children. In A. Sinclair, R. J. Jarvella, \& W. J. M. Levelt (Eds.), The child's conception of language (pp. 97-132). New York: Springer.

Jarvis, S., \& Pavlenko, A. (2008). Crosslinguistic influence in language and cognition. New York: Routledge. 
Jia, G., Aaronson, D., \& Wu, Y. H. (2002). Long-term language attainment of bilingual immigrants: predictive factors and language group differences. Applied Psycholinguistics, 23, 599-621.

Jia, G., \& Fuse, A. (2007). Acquisition of English grammatical morphology by native Mandarin-speaking children and adolescents: age-related differences. Journal of Speech, Language, and Hearing Research, 50, 1280-99.

Katz, L. A. (2004). An investigation of the relationship of morphological awareness to reading comprehension in fourth and sixth grades (Unpublished doctoral dissertation). University of Michigan, Ann Arbor, MI.

Kurinski, E., \& Sera, M. D. (2011). Does learning Spanish grammatical gender change English-speaking adults' categorization of inanimate objects? Bilingualism: Language and Cognition, 14, 203-20.

Leikin, M., Schwartz, M., \& Share, D. L. (2010). General and specific benefits of bi-literate bilingualism: a Russian-Hebrew study of beginning literacy. Reading and Writing, 23, 269-92.

Lipka, O., Siegel, L. S., \& Vukovic, R. (2005). The literacy skills of English language learners in Canada. Learning Disabilities Research and Practice, 20, 30-49.

Marchman, V. A., Fernald, A., \& Hurtado, N. (2010). How vocabulary size in two languages relates to efficiency in spoken word recognition by young Spanish-English bilinguals. Journal of Child Language, 37, 817-40.

McBride-Chang, C., Cho, J. R., Liu, H., Wagner, R K., Shu, H., Zhou, A., ... \& Muse, A. (2005). Changing models across cultures: associations of phonological awareness and morphological structure awareness with vocabulary and word recognition in second graders from Beijing, Hong Long, Korea, and the United States. Journal of Experimental Child Psychology, 92, 140-60.

McGuinness, D. (2005). Language development and learning to read. Cambridge, MA: MIT Press.

Mokhtari, K., \& Thompson, B. (2006). How problems of reading fluency and comprehension are related to difficulties in syntactic awareness skills among fifth graders. Reading Research and Instruction, 46, 73-94.

Moyle, M. J., Ellis Weismer, S., Lindstrom, M., \& Evans, J. (2007). Longitudinal relationships between lexical and grammatical development in typical and late talking children. Journal of Speech, Language, and Hearing Research, 50, 508-28.

Nagy, W. E. (2007). Metalinguistic awareness and the vocabulary-comprehension connection. In R. K. Wagner, A. E. Muse, \& K. R. Tannenbaum (Eds.), Vocabulary acquisition: implications for reading comprehension (pp. 52-77). New York: Guilford Press.

Nation, I. S. P. (2013). Learning vocabulary in another language (2nd ed.). Cambridge University Press.

Nation, K., \& Snowling, M. (2000). Factors influencing syntactic awareness skills in normal readers and poor comprehenders. Applied Psycholinguistics, 21, 229-41.

Nicoladis, E. (2006). Cross-linguistic transfer in adjective-noun strings by preschool bilingual children. Bilingualism: Language and Cognition, 9, 15-32.

Nunes, T., \& Bryant, P. (Eds.) (2004). Handbook of children's literacy. Dordrecht: Kluwer Academic Publishers.

Paradis, J. (2010). Bilingual children's acquisition of English verb morphology: effects of language exposure, structure complexity, and task type. Language Learning, 60, 651-80.

Paradis, J., Nicoladis, E., Crago, M., \& Genesee, F. (2011). Bilingual children's acquisition of the past tense: a usage-based approach. Journal of Child Language, 38, 554-78.

Rainey, V. R., Davidson, D., \& Li-Grining, C. (2016). Executive functions as predictors of syntactic awareness in English monolingual and English-Spanish bilingual language brokers and nonbrokers. Applied Psycholinguistics, 37, 963-95.

Reder, F., Marec-Breton, N., Gombert, J. E., \& Demont, E. (2013). Second-language learners' advantage in metalinguistic awareness: a question of languages' characteristics. British Journal of Educational Psychology, 83, 686-702.

Ricciardelli, L. A. (1993). Two components of metalinguistic awareness: control of linguistic processing and analysis of linguistic knowledge. Applied Psycholinguistics, 14, 349-67.

Schmidt, R. L. (2004). Urdu: an essential grammar. New York: Routledge.

Simard, D., \& Fortier, V. (2007). Metasyntactic ability development among submersion and French native elementary school children: investigation of task demand. In Z. Han (Ed.), Understanding second language processes (pp. 160-75). Clevedon: Multilingual Matters.

Simard, D., Fortier, V., \& Foucambert, D. (2013). Measuring the metasyntactic ability of Portuguese speaking children living in a French speaking environment. Bilingualism: Language and Cognition, $16,19-31$. 
Simard, D., Labelle, M., \& Bergeron, A. (2017). Measuring metasyntactic abilities: on a classification of metasyntactic tasks. Journal of Psycholinguistic Research, 46, 433-56.

Tabachnick, G. G., \& Fidell, L. S. (2007). Using multivariate statistics (5th ed.). Boston, MA: Allyn and Bacon.

Tunmer, W. E., \& Grieve, R. (1984). Syntactic awareness in children. In W. E. Tunmer, C. Pratt, \& M. L. Herriman (Eds.), Metalinguistic awareness in children: theory, research, and implications (pp. 92104). Berlin: Springer-Verlag.

Yip, V. (2013). Simultaneous language acquisition. In F. Grosjean \& L. Ping (Eds.), The psycholinguistics of bilingualism (pp. 119-36). Malden, MA: Wiley-Blackwell.

Cite this article: Davidson D, Vanegas SB, Hilvert E, Rainey VR, Misiunaite I (2019). Examination of monolingual (English) and bilingual (English/Spanish; English/Urdu) children's syntactic awareness. Journal of Child Language 46, 682-706. https://doi.org/10.1017/S0305000919000059 